5.

Derecho del trabajo 

Revista de Derecho

de la Pontificia Universidad Católica de Valparaíso

XXX (Valparaíso, Chile, $1^{\text {er }}$ Semestre de 2008)

[pp. 265 - 291]

\title{
EL RECONOCIMIENTO DE LA LIBERTAD SINDICAL Y EL PROBLEMA DE LA REPRESENTACIÓN DE LOS TRABAJADORES EN LA NEGOCIACIÓN COLECTIVA
}

[The Acknowledgement of Freedom of Association and the Problem of the Worker's Representation in the Collective Negotiation]

\author{
Eduardo Caamaño Rojo* \\ Pontificia Universidad Católica de Valparaíso
}

\begin{abstract}
RESUMEN
El trabajo pretende poner de manifiesto la necesidad de perfeccionar la actual institucionalidad laboral de tal forma que pueda asegurar un ejercicio pleno y efectivo de la negociación colectiva, en el entendido que un Estado de Derecho, para poder ser tal, debe velar por que todos los ciudadanos tengan la posibilidad cierta de materializar en su vida cotidiana las libertades y garantías implícitas en el contenido esencial de los derechos fundamentales. La negociación colectiva, en particular, y la libertad sindical, en general, son libertades que reclaman que todos los trabajadores tengan la opción concreta de poder ejercerlas y no se conviertan en un privilegio reservado a un número limitado de personas. Con todo, debido a la amplitud de factores que involucra un examen de esta naturaleza,
\end{abstract}

\begin{abstract}
This work intends to evidence the need to improve the present labour institutionality so that it can ensure a complete and effective exercise of collective negotiation, based on the understanding that a Constitutional State, to be such, must watch over all the citizens to have the true possibility of materializing in their daily lives the liberties and guarantees implicit in the essential content of the fundamental rights. Collective negotiation, in particular, and liberties of association, in general, are freedoms that claim that all the workers have a concrete option to be able to exert them and they don't become a privilege reserved for a limited number of people. However, due to the enormous amount of factors that involve an examination of this nature, we have chosen to limit the issue to
\end{abstract}

* Doctor en Derecho por la Universidad de Colonia, Alemania; Profesor de Derecho del Trabajo en la Facultad de Derecho de la Pontificia Universidad Católica de Valparaíso. Dirección postal: Avda. Brasil 2950, Valparaíso, Chile. Correo electrónico: eduardo.caamano@ucv.cl. 
se ha optado por circunscribirlo al tema de la equiparación legal de sindicatos y grupos transitorios de trabajadores como sujetos dotados de la facultad de negociar colectivamente.

Palabras Clave: Libertad sindical - Negociación colectiva - Sindicato - Trabajo. the subject of the legal comparison of unions and temporary groups of workers as subjects granted with the power of collectively negotiation.

KeYwords: Freedom of association - Collective negotiation - Trade Union - Work.

\section{INTRODUCCIÓN}

La última Encuesta Laboral elaborada el año 2007 por la Dirección del Trabajo, la ENCLA 2006, muestra resultados alarmantes en materia de negociación colectiva que reclaman con urgencia la necesidad de ahondar el debate sobre el real grado de vigencia de este derecho en Chile. En efecto, según la encuesta ${ }^{1}$, la proporción de empresas que ha negociado colectivamente en los últimos 5 años no alcanza al $10 \%$, vale decir, la negociación colectiva sólo ha tenido lugar en una de cada diez empresas, lo que configura una situación preocupante que dimensiona el mínimo impacto de este instrumento en las relaciones laborales del país. De igual manera, la ENCLA ha permitido establecer que en Chile la proporción de empresas con instrumento colectivo vigente alcanza al 8,7\% y, por tanto, en su complemento, en el restante $91,3 \%$ de las empresas rigen condiciones contractuales basadas únicamente en la negociación individual entre empleadores y trabajadores.

Los resultados citados dan cuenta de un escenario muy complejo por las innegables repercusiones que la falta de una adecuada cobertura de la negociación colectiva supone en el ámbito económico y social, pues estos resultados son indiciarios de la enorme inequidad en la distribución de los ingresos que existe en el país. En este sentido, por ejemplo, la misma encuesta permitió acreditar que en Chile el $65,6 \%$ de la fuerza laboral percibe remuneraciones inferiores a los $\$ 405.000^{2}$, lo que a todas luces refuerza la necesidad de replantear el actual marco jurídico sobre la negociación colectiva, en vistas a contribuir desde la perspectiva jurídica laboral

${ }^{1}$ Dirección del Trabajo, Encuesta Laboral, ENCLA 2006, p. 93 s. Documento disponible en: www.dt.gob.cl. Véase también: Celhay, Pablo - Gil, Diego, Sindicalización y negociación colectiva, Estudio para el Consejo Asesor Presidencial de Trabajo y equidad, pp. 5 s., disponible en: www.trabajoyequidad.cl/documentos/ temp/Sindicalización.pdf.

${ }^{2}$ Dirección del Trabajo, Encuesta Laboral, ENCLA 2006, p. 44. 
a crear condiciones que posibiliten aumentar el número de trabajadores que puedan acceder a un mejoramiento de sus condiciones salariales y de trabajo por la vía de los acuerdos colectivos con sus empleadores.

Con todo, la relevancia del perfeccionamiento del ordenamiento laboral en materia colectiva está dada también, porque permite asentar las bases jurídicas para el desarrollo de un diálogo social sólido y fructífero, el que se ha venido configurando como el camino más efectivo para generar acuerdos amplios y diversos que faciliten a trabajadores y empleadores, de conformidad a sus distintas realidades, necesidades e intereses, hacer frente a los imprevistos vaivenes y a los constantes cambios de la economía globalizada ${ }^{3}$.

Por otra parte, en relación con lo antes expuesto, no se puede obviar la especial significación que posee la negociación colectiva en cuanto constituye un derecho fundamental de los trabajadores consagrado tanto en la Constitución Política de la República, en su artículo 19 № 16 inciso 5, como en múltiples instrumentos internacionales ratificados por Chile, tales como la Declaración Universal de los Derechos Humanos o el Pacto Internacional de Derechos Económicos, Sociales y Culturales. A su vez, a nivel supranacional y en el ámbito estrictamente laboral, la negociación colectiva, en particular, y la libertad sindical, en general, han adquirido el valor de derechos fundamentales de validez universal, según se desprende claramente de los Convenios $\mathrm{N}^{\circ} 87$ y $\mathrm{N}^{\circ} 98$ de la Organización Internacional del Trabajo (OIT), a los que nos referiremos en un acápite posterior de este estudio.

Por lo todo anterior, entonces, la necesidad de estudiar cambios normativos que perfeccionen nuestra actual institucionalidad laboral en materia de negociación colectiva obedece no sólo a la urgencia de dar respuesta a las condiciones laborales desfavorables que afectan a un porcentaje considerable de trabajadores, sino que también responde al deber de promover y hacer realidad el pleno ejercicio de este derecho fundamental, dando así cumplimiento a los tratados ratificados por el país, cuyas exigencias tienen implicancias tanto jurídicas como económicas en el plano internacional. Por cierto, para ilustrar esta situación cabe señalar la limitada efectividad de la negociación colectiva y la escasa cobertura de los instrumentos colectivos dan pie para que se configuren situaciones de dumping social que pueden comprometer la credibilidad del país frente a sus socios comerciales, pues ello redunda en que nuestros productos de exportación puedan ser

${ }^{3}$ Ver: Comisión de las Comunidades Europeas, Libro Verde. Modernizar el Derecho Laboral para afrontar los retos del siglo XXI (Bruselas, 22 de noviembre de 2006, COM, 2006), p. 708 final. 
más competitivos no en base a su calidad o a la eficiencia de sus procesos productivos, sino que gracias al menor costo laboral incorporado al precio final. Situaciones como ésta pueden tener graves consecuencias, pues permitirían dar lugar, por ejemplo, a que nuestro país no esté cumpliendo cabalmente las obligaciones asumidas en materia laboral en el Tratado de Libre Comercio con EE.UU4 .

En el marco de lo expuesto precedentemente, el presente artículo pretende poner de manifiesto la necesidad de avanzar en el perfeccionamiento de nuestra institucionalidad laboral de forma tal que ésta pueda asegurar un ejercicio efectivo de la negociación colectiva, en el entendido que un Estado de Derecho, para poder ser tal, debe velar por que todos los ciudadanos tengan la posibilidad cierta de materializar en su vida cotidiana las libertades y garantías implícitas en el contenido esencial de los derechos fundamentales. La negociación colectiva, en particular, y la libertad sindical, en general, son libertades que reclaman que todos los trabajadores tengan la opción concreta de poder ejercerlas y no se conviertan, como lo demuestran las estadísticas citadas, en un privilegio reservado a un número limitado de personas. Así, entonces, el estudio propuesto persigue aportar una visión crítica sobre el real alcance que conlleva el reconocimiento de la libertad sindical en nuestro actual ordenamiento jurídico laboral, el que, según se establecerá, es aún heredero de una visión limitativa de este derecho fundamental que se mantiene arraigada a pesar de la ratificación de los principales Convenios de la OIT sobre la materia. Con todo, debido a la amplitud de factores que involucra un examen crítico de esta naturaleza, se ha optado por restringir el análisis a la problemática que supone el hecho que en nuestro país se equipare a los sindicatos y a los grupos transitorios de trabajadores como sujetos dotados de la facultad de negociar colectivamente, lo cual presenta de por sí un marco representativo para contrastar la pugna de visiones sobre los alcances jurídicos de la libertad sindical y la incidencia del modelo económico neoliberal en la conformación de la legislación laboral vigente.

\section{ANTECEDENTES DEL ACTUAL MARCO NORMATIVO SOBRE LA NEGOCIACIÓN COLECTIVA}

La negociación colectiva se encuentra regulada en Chile en el libro IV del Código del Trabajo (CdT) y su contenido medular sigue correspondiendo al diseño impuesto por el Plan Laboral de 1978, concretado nor-

${ }^{4}$ Sobre la materia: CaAmaño Rojo, Eduardo, Contenido laboral del Tratado de Libre Comercio con los Estados Unidos de Norteamérica, en Revista Laboral Chilena 118 (julio 2003), pp. 79 s. 
mativamente en el Decreto Ley (DL) $\mathrm{N}^{\circ} 2.758$. Esta normativa obedeció al interés del Régimen Militar de implementar un marco regulador del ejercicio de los derechos colectivos del trabajo que estuviera en concordancia y al servicio de un nuevo modelo económico de corte neoliberal, abierto al comercio internacional y en el que se promovían como verdaderos ejes centrales de su funcionamiento el derecho de propiedad, la libertad de empresa y la búsqueda por eliminar restricciones o barreras que dificultaran o encarecieran la libre iniciativa privada en materia económica. ${ }^{5}$ Por este motivo, la normativa de aquel entonces, sin perjuicio de no haber sido consensuada democráticamente, representó un abrupto quiebre con la anterior institucionalidad laboral consolidada a partir del CdT de 1931, en la que, acorde con la visión inicial de fuerte valorización y promoción de los derechos colectivos laborales, se reforzaba el reconocimiento y eficacia de los derechos de sindicación, de negociación colectiva y de huelga.

Nos encontramos, por tanto, con una legislación que si bien pretendió revolucionar, a su singular modo, la legislación existente desde hacía medio siglo, excluyendo la participación estatal, no hizo sino limitar aún más el ámbito de la libertad sindical en lo pertinente al derecho a negociar colectivamente. Fueron signos visibles de ello: la reducción de la negociación colectiva vinculante u obligatoria al ámbito exclusivo de la empresa, el privilegio de la negociación individual por sobre la colectiva, el fomento de negociaciones colectivas informales, incluso sin participación sindical y sin mecanismos clásicos de igualación de poderes en el ámbito de la negociación colectiva (el fuero y la huelga); la excesiva reglamentación de la huelga y la restricción de su ejercicio; el desincentivo de la sindicalización; la limitación y prohibición del derecho a negociar colectivamente para un amplio grupo de trabajadores, la escasa preocupación por la necesidad que la negociación colectiva se verifique con actores debidamente informados, así como una precaria tutela de tal derecho, por medio de la consagración de una mera sanción pecuniaria de baja cuantía por las prácticas desleales en la negociación colectiva ${ }^{6}$.

Esta normativa incorporada por el $\mathrm{DL} \mathrm{N}^{\circ} 2.758$, que luego dio forma al CdT de 1987, fue objeto de diversas modificaciones por los Gobiernos de la Concertación al momento de reinstaurarse la democracia en el país,

${ }^{5}$ En detalle: Rojas MiÑo, Irene, Las reformas laborales al modelo normativo de negociación colectiva del Plan Laboral, en Revista Ius et Praxis 13 (2007) 2, pp. $196 \mathrm{s.}$

${ }^{6}$ Véase: Rojas Miño, Irene, Las reformas laborales, cit. (n. 5), pp. 201-202; ToLEDO, César, Alcances de la negociación colectiva en Chile, Sociedad Chilena de Derecho del Trabajo (2007), documento sin editar; CaAmaño Rojo, Eduardo, La tutela jurisdiccional de la libertad sindical, en Revista de Derecho, Universidad Austral de Chile 19 (julio 2006), pp. 77 s. 
lo que se hizo fundamentalmente a través de las Leyes $\mathrm{N}^{\circ} 19.049,19.069 \mathrm{y}$ 19.759. Sin embargo, si se efectúa un balance general de los alcances de las modificaciones legales más relevantes que ha experimentado la legislación laboral desde el año 1991 hasta la fecha no se puede estar muy conforme con el resultado final. Las reformas, particularmente la del año 2001, luego de la ratificación de los Convenios medulares de la OIT en materia de libertad sindical, se han centrado fundamentalmente en reforzar y liberalizar el ejercicio del derecho de sindicación en un amplio sentido, dejando de lado modificaciones más sustanciales a la normativa heredada del Régimen Militar en materia de negociación colectiva y de huelga. Esto último marca un desequilibrio en la situación y en el rol de los actores sociales laborales, como a su vez, reafirma una inconsecuencia en el reconocimiento de los derechos laborales que permite explicar y entender, pero no justificar, los limitados alcances que tiene hoy la negociación colectiva en Chile, según lo ha demostrado la ENCLA 2006 .

Ahora bien, las causas que explican la supervivencia hasta la fecha de un modelo tan restrictivo de negociación colectiva pueden ser de diversa naturaleza, primando según nuestro parecer, aquellas de índole económico o político, pues dan cuenta de visiones y de principios contrapuestos, conforme a los cuales pareciera subvalorarse la importancia de reformar el actual ordenamiento jurídico laboral en contraste con la sobrevaloración que se otorga a índices macro y microeconómicos de carácter abstracto $y$, por lo mismo, alejados de la sensibilidad y de las necesidades del ciudadano común que forma parte de la fuerza laboral. Por tal motivo es dable sostener que aquellas consideraciones centradas en la necesidad de consolidación del modelo económico o de mantener las condiciones que han hecho posible un crecimiento sostenido del país en los últimos años, no pueden impedir un diálogo o la discusión sobre los alcances que presenta la actual legislación laboral y que repercuten directamente en las cuestionables condiciones de trabajo en que se encuentra un porcentaje considerable de trabajadores y trabajadoras chilenos.

De igual modo, no se pueden perder de vista las transformaciones

${ }^{7}$ Un dato relevante para ilustrar lo anterior es que, hasta la fecha, nuestro país no ha ratificado el Convenio $\mathrm{N}^{\circ} 154$ de la OIT de 1981 sobre promoción del derecho a la negociación colectiva, ni se vislumbra una clara voluntad política de avanzar en ese sentido. Sobre la extensión de la negociación colectiva en Chile, véase también: Celhay, Pablo - Gil, Diego, Sindicalización y negociación colectiva, cit. (n. 1), pp. 5 s.; Salinero, Jorge - Rozas, María - Tapia, Andrés, 20 años de afiliación sindical $y$ de negociación colectiva en Chile: problemas y desafios, en Cuaderno de Investigación No 29, Departamento de Estudios de la Dirección del Trabajo (noviembre 2006), disponible en: http://www.dt.gob.cl/documentacion/1612/article-94126.html. 
económicas, sociales y culturales que ha experimentado el actual mundo globalizado en el que se desarrollan las actividades productivas y de intercambio y que nada tienen que ver con el escenario a partir del cual se consolidó el Derecho del Trabajo a principios del siglo XX o ni siquiera con la visión del mundo imperante a fines de la década de los 70 y a principios de los 80, cuando se diseńó e implementó el Plan Laboral. ${ }^{8}$ Por lo tanto, el estudio de la implicancia de la actual normativa en materia de negociación colectiva debe ser vista también como una oportunidad para refundar las bases a partir de las cuales deben articularse las relaciones laborales colectivas en el nuevo siglo, que hagan posible la consolidación de un diálogo social libre y en condiciones de equivalencia que pueda dar respuesta a las múltiples y diversas exigencias que presenta y presentará el mercado laboral. ${ }^{9}$ Esto último hasta la fecha no ha sido posible de alcanzar, debido a las fuertes restricciones que limitan el ejercicio del derecho a negociar colectivamente, dando cuenta, además, de un modelo que privilegia los intereses empresariales por sobre los intereses de los trabajadores, en vez de crear las condiciones de equilibrio de poderes que son el presupuesto indispensable para el pleno ejercicio de la libertad sindical, en esta búsqueda legítima de trabajadores y empleadores organizados colectivamente para hacer valer sus intereses en el plano laboral y económico ${ }^{10}$.

\section{LA LIBERTAD SINDICAL COMO FUNDAMENTO DE LA NEGOCIACIÓN COLECTIVA}

Para una adecuada delimitación del tema objeto de este estudio, es necesario hacer una breve referencia a la noción de la libertad sindical implícita en el CdT de 1987, en el cual se sistematizó la legislación que dio

${ }^{8}$ Véase: Franco, Julio - Marcos-Sánchez, José - Benoit, Christine, Negociación colectiva articulada. Una propuesta estratégica (Lima, OIT/PLADES, 2001), p. $16 \mathrm{~s}$.

${ }^{9}$ Este es el caso, por ejemplo, del creciente interés de trabajadores y trabajadoras por conciliar sus responsabilidades laborales y familiares, el que no encuentra cabida debido al limitado alcance y contenido que puede tener la negociación colectiva en virtud de lo dispuesto por el artículo 317 del CdT. Véase: CaAmaño Rojo, Eduardo, Oportunidades de conciliación de trabajo y vida familiar en la legislación laboral chilena, en Revista de Derecho de la Pontificia Universidad Católica de Valparaíso 29 (2007), pp. 171 s.

${ }^{10}$ En efecto, existen diversas disposiciones del CdT en materia de negociación colectiva, en las que "la balanza" se inclina abiertamente a favor de los intereses del empleador, lo que se traduce en la aceptación de su última oferta, poniendo fin así a la negociación. Véase: artículos 370 inciso 3; 373 y 374 del CdT. 
forma normativa al Plan laboral ${ }^{11}$ y que luego subyacerá en las versiones sistematizadas posteriores del CdT hasta la última gran reforma laboral introducida el año 2001 por la Ley $N^{\circ} 19.759$.

Es así, que si se examina desde una perspectiva general la legislación de la época, es posible inferir que ella asumía una concepción restrictiva de las facultades inherentes a la noción de libertad sindical, lo que encontraba también un correlato en la visión de la doctrina iuslaboralista tradicional chilena $^{12}$, y se traducía, en concreto, en una exclusión del ámbito funcional de la libertad sindical, es decir, el ejercicio de la actividad sindical en defensa de los intereses colectivos de los trabajadores, poniendo el acento, básicamente, en las facultades de constituir, organizar, afiliarse y desafiliarse de una organización sindical. Por lo anterior, desde este punto de vista, se tendía generalizadamente a asociar la libertad sindical de manera exclusiva con el derecho de sindicación ${ }^{13}$, lo que coincidía, a su vez, con la estructura normativa adoptada por nuestra Constitución Política de la República (CPR) y una lectura meramente formalista y no finalista de sus disposiciones, en razón de que el texto constitucional consagra separadamente el derecho de sindicación (artículo 19 No 19) del derecho a negociar colectivamente (artículo $19 \mathrm{~N}^{\circ} 16$ inciso 5) y asume un reconocimiento negativo y limitado del derecho a huelga (artículo 19 No 16 inciso 6).

Atendido lo precedentemente expuesto, se puede afirmar que la legislación laboral emitida durante el Régimen Militar asumía una visión limitada de la libertad sindical, no acorde con los principios y derechos básicos reconocidos por los Convenios No 87 y No 98 de la OIT ${ }^{14}$. Aun

\footnotetext{
${ }^{11}$ Nos referimos en concreto al DL No 2.200 de 1978 sobre contrato de trabajo y las demás relaciones laborales entre empleadores y trabajadores, al DL No 2.756 de 1979 sobre organización sindical y al DL No 2.759 de 1979 sobre negociación colectiva, sin perjuicio de otras leyes laborales posteriores, incluidas luego en el CdT de 1987. Véase sobre la materia: Rojas Miño, Irene, Las reformas laborales, cit. (n. 5), pp. $201 \mathrm{~s}$.

${ }^{12}$ Así por ejemplo, Macchiavello, Guido, Derecho Colectivo del Trabajo (Santiago, Editorial Jurídica, 1989), p. 122.

${ }^{13}$ Véase: Ugarte Cataldo, José Luis, Libertad sindical y Constitución: cómo superar una vieja lectura, en Revista Laboral Chilena (mayo 2000), pp. 71-72; GAMONAL Contreras, Sergio, Derecho Colectivo del Trabajo (Santiago, Editorial LexisNexis, 2002), p. 87.

${ }^{14}$ Cabe hacer presente que durante el Régimen Militar no se ratificaron estos Convenios, lo que recién tuvo lugar el año 1999. Sobre la materia: Corvera, Diego - Gumucio, J., Las normas de los Convenios 87 y 98 de la OIT y su relación con la normativa interna chilena, en Revista Laboral Chilena (julio 2000), pp. 65 s.; THAyer Arteaga, William, Hacia una nueva cultura laboral. Efectos y proyecciones de la ratificación de los Convenios 87 y 98 de la OIT (Santiago, Fundación Científica y Tecnológica, Asociación Chilena de Seguridad, 1999).
} 
cuando pudiera sostenerse lo contrario ${ }^{15}$, desconociendo, por tanto, la evolución conceptual de esta libertad que, solo en sus orígenes se entendió referida apenas al reconocimiento del derecho de los trabajadores a constituir sindicatos, pero que luego dio paso a reconocerle un contenido complejo que incluye derechos positivos (de hacer) y negativos (de no hacer), tanto en el plano individual como colectivo. ${ }^{16}$ En todo caso, basta dejar de manifiesto que la ratificación por parte de Chile el año 1999 de los principales instrumentos internacionales sobre la libertad sindical, como asimismo, la evolución normativa interna en materia de relaciones colectivas de trabajo que ha tenido lugar desde comienzos de la década de los noventa, permiten, en los albores del siglo XXI, sustentar clara y firmemente una noción amplia de esta libertad $\mathrm{y}$, ante todo, proclamar su carácter de atributo esencial de toda persona, es decir, su calidad de derecho humano fundamental ${ }^{17}$.

Por lo anterior, la libertad sindical se puede definir como: "el derecho que asiste a los trabajadores para constituir organizaciones, afiliarse o desafiliarse a ellas, a darse su propia normativa sin intervención de terceros $\mathrm{y}$, especialmente, el derecho al ejercicio de la actividad sindical por medio de aquellas acciones tendientes a la defensa y promoción de los intereses que le son propios, en particular, la negociación colectiva y el derecho a huelga" ${ }^{18}$. En base a esta definición de libertad sindical se puede concluir

${ }^{15}$ Como lo plantea Ugarte, una de las ventajas de la idea restringida de libertad sindical que explica su éxito y permanencia en nuestra cultura jurídica laboral obedece a que lo formal y exiguo de su contenido, sólo referido a aspectos organizativos, impone una extensión tan mínima de protección que difícilmente es posible generar regulaciones estatales o conductas que la violenten o restrinjan. En dicho caso, aun cuando el Estado se limite a proteger la libre organización y se desentienda de los fines perseguidos con la libre asociación y de los mecanismos para lograrlos, no brindando mayor amparo a la actividad sindical, se podría entender, con dosis de buena voluntad, que ha cumplido satisfactoriamente con su deber de protección de la libertad sindical. Ugarte Cataldo, José Luis, Libertad sindicaly Constitución, cit. (n. 13), p. 71.

${ }^{16}$ En este sentido: Ermida, Oscar, Sindicatos en libertad sindical (2a edición, Montevideo, Fundación de Cultura Universitaria, 1999), p. 29.

${ }^{17}$ Así se desprende claramente de lo previsto por la Declaración Universal de Derechos Humanos (artículo 20 No 1 y 23 No 4); el Pacto Internacional de Derechos Civiles y Políticos (artículo 22); el Pacto Internacional de Derechos Económicos y Sociales (artículo 8); la Declaración Americana de Derechos y Deberes del Hombre (artículo XXII) y la Convención Americana de Derechos Humanos (artículo 16). Además, de acuerdo a lo ya señalado, esta concepción es compartida por la OIT, por ejemplo, en el apartado 2 de la Declaración relativa a los Principios y Derechos Fundamentales en el Trabajo de 1998.

${ }^{18}$ Varas Castillo, Mario, Libertad sindical y negociación colectiva en Chile: un 
que forman parte de su contenido esencial el derecho de sindicación (faz orgánica) y naturalmente el derecho a hacer valer los intereses colectivos de los trabajadores organizados, mediante la acción reivindicativa y participativa ${ }^{19}$, lo que se canaliza a través del ejercicio de los derechos de negociación colectiva y de huelga ${ }^{20}$ (faz funcional) ${ }^{21}$. En concordancia con lo anterior, se plantea que la libertad sindical es una libertad civil y política. Es una libertad civil, ya que consagra el derecho de los privados de reivindicar cierta autonomía en la regulación de los fenómenos sociales, así

diagnóstico de la Ley $N^{\circ} 19.759$, en Boletín Oficial de la Dirección del Trabajo (agosto 2003), pp. 3 s. En el Derecho Comparado, para dar un ejemplo, la doctrina la define como: "el derecho de los trabajadores a fundar sindicatos y a afiliarse a los de su elección, así como el derecho de los sindicatos al ejercicio libre de las funciones que les son atribuidas constitucionalmente para la defensa de los intereses del trabajo asalariado." En este sentido: Palomeque, Manuel - Álvarez de la Rosa, Manuel, Derecho del Trabajo ( $11^{\circ}$ edición, Madrid, Editorial Centro de Estudios Ramón Areces, 2003), p. 431.

${ }^{19}$ Ermida, Oscar, Sindicatos en libertad sindical, cit. (n. 16), p. 47: “Además de lo participativo y lo reivindicativo, modernamente el sindicato desarrolla numerosas e importantes actividades laterales, tales como, entre otras, las relacionadas con la formación profesional, lo cultural, la rehabilitación y protección de minusválidos, la salud, las obras sociales de diverso tipo [...]". Un correlato de lo anterior se encuentra en nuestra legislación laboral si se analizan los fines amplios reconocidos a los sindicatos en el artículo 220 del CdT o a las federaciones y confederaciones en el artículo 267 del mismo cuerpo legal.

${ }^{20}$ En igual sentido: ERMida, Oscar, Sindicatos en libertad sindical, cit. (n. 16), p. 45; OIT, Derechos fundamentales en el trabajo y normas internacionales del trabajo (Madrid, edición del Ministerio del Trabajo y Asuntos Sociales, 2003), p. 23 s. Una concepción amplia de la libertad sindical se acepta también el Derecho alemán en razón de lo dispuesto por el artículo 9 inciso 3 de la Constitución de ese país. Así lo manifiesta: Epping, Volker, Grundrechte (2a edición, Berlín, Editorial Springer, 2005), pp. 331-338; Preis, Ulrich, Arbeitsrecht. Praxis-Lehrbuch zum Kollektivarbeitsrecht (Colonia, Editorial Dr. Otto Schmidt, 2003), pp. 22-24.

${ }^{21}$ En el derecho español, la jurisprudencia del Tribunal Constitucional ha resuelto que el derecho de libertad sindical comprende no sólo el derecho de constituir sindicatos y de afiliarse a los mismos, sino también el derecho a que los sindicatos fundados realicen las funciones que de ellos es dable esperar, de acuerdo con el carácter democrático del Estado y con las coordenadas que a esta institución hay que reconocer, a las que se puede denominar contenido esencial (sentencias de fechas 29/11/1982 y 25/4/1984). Estos derechos necesarios a incluir en el contenido del derecho de libertad sindical constitucionalmente reconocido a todos los sindicatos son, sin duda alguna, el de negociación colectiva, huelga e incoación de conflictos colectivos, los que constituyen un núcleo mínimo e indisponible, sin el cual el propio derecho de libertad sindical no sería reconocible (sentencias de fecha 31/3/1986 y 25/1/1988). En detalle: Sala Franco, Tomás; Albiol Montecinos, Ignacio, Derecho Sindical (9a edición, Valencia, Editorial Tirant Lo Blanch, 2003), p. 45. 
como la libertad de las agrupaciones colectivas de no ser intervenidas por el Estado y de constituir un ordenamiento normativo especial y autónomo del estatal. A su vez, se trata de una libertad política, ya que comprende el poder de resistencia colectiva de los ciudadanos y de participación en las estructuras y funciones estatales ${ }^{22}$.

Asimismo, compartiendo lo sostenido por Osvaldo Mantero ${ }^{23}$, cabe sostener que la circunstancia de que la libertad sindical se encuentre reconocida en una gran parte de las constituciones modernas y en los instrumentos internacionales sobre derechos fundamentales, no es la causa de que ésta sea un derecho fundamental, sino la consecuencia de que lo es. En efecto, para el autor citado, la calidad de derecho fundamental de la libertad sindical es consecuencia de su reconocimiento como tal por la conciencia jurídica universal, siendo ese reconocimiento, al igual que respecto del resto de los derechos fundamentales, el producto de un largo proceso de luchas y enfrentamientos ${ }^{24}$. De esta manera, entonces, la inclusión de la libertad sindical en los instrumentos sobre derechos humanos se produce en medio de una transformación profunda del concepto de derecho fundamental, cuyo centro se encuentra en la propia libertad sindical y en otros derechos relacionados con el trabajo, pues este reconocimiento está íntimamente relacionado con dos transformaciones del concepto de estas garantías esenciales del ser humano: por una parte, el reconocimiento de los derechos sociales y, por otra, la aceptación de derechos cuyo titular no es el individuo, sino que un conjunto de personas ${ }^{25}$.

En plena concordancia con lo anterior, las concepciones actuales sobre la libertad sindical recalcan que ella no se limita solo a los aspectos individuales de su ejercicio (libertad de constitución y afiliación), sino que se proyecta necesariamente a la tutela y promoción de las expresiones de

${ }^{22}$ En este sentido: Veneziani, B., Statu e autonomia colletiva, diritto sindicale italiano e comparato (Bari, Cacucci, 1992), pp. 54-55, citado por GAMONAL ConTRERAs, Sergio, Daño moral en el contrato de trabajo (Santiago, Editorial LexisNexis, 2005), pp. 101-102.

${ }^{23}$ Mantero, Osvaldo, Derecho sindical (2a reimpresión, Montevideo, Fundación de Cultura Universitaria, 2004), pp. 76-77.

${ }^{24}$ En relación con nuestra realidad nacional se señala que: "La afirmación de principios como el respeto a los trabajadores y a sus organizaciones sindicales serán una de las principales consecuencias de las luchas del primer decenio de nuestro siglo y es necesario considerarlos como antecedentes para explicar la formación democrática de Chile." En este sentido: Ortiz, Fernando, El movimiento obrero en Chile (Santiago, Lom Ediciones, 2005), p. 21.

${ }^{25}$ En cuanto a la concepción de la libertad sindical como derecho fundamental véase también: Gamonal Contreras, Sergio, Derecho Colectivo del Trabajo, cit. (n. 13), p. 64 s. 
carácter colectivo que le son propias, esto es, el ejercicio de derechos que dicen relación con el desarrollo de la actividad sindical en su faz funcional, vinculado específicamente al derecho de negociación colectiva y derecho a huelga ${ }^{26}$. Este es también el planteamiento sostenido por el Comité de Libertad Sindical de la OIT $^{27}$. Además, puede afirmarse que esta sería la concepción de la libertad sindical que consagra la Constitución Política de la República, si se analizan de manera armónica e integrada las disposiciones de los artículos $19 \mathrm{~N}^{\circ} 16,19$ y 26 de la $\mathrm{CPR}^{28}$, en concordancia con los principios contenidos en los mencionados Convenios $\mathrm{N}^{\circ} 97$ y 98 de la OIT ratificados por Chile.

Por lo tanto, la evolución natural experimentada por la noción de libertad sindical y su reforzamiento a nivel interno luego de la ratificación de los principales instrumentos internacionales del trabajo sobre la materia y las reformas introducidas a la legislación nacional desde el retorno a la democracia en el país, reclaman de una visión amplia e integradora de esta libertad que va naturalmente asociada al ejercicio de un derecho fundamental. Por tal razón, es un deber ineludible de todo Estado de Derecho promover y dar de eficacia a las garantías fundamentales, dotándolas de adecuados mecanismos de tutela y materializando, de ser ello pertinente, las modificaciones legales que puedan ser necesarias para poner fin a las restricciones que las limiten y hacer realidad sus posibilidades de ejercicio por todos los ciudadanos, evitando que se desvirtúen, transformándose en un privilegio de pequeños grupos. De allí, por cierto, que las preocupantes cifras sobre el alcance de la negociación colectiva en Chile evidenciadas por la ENCLA 2006 deben constituir un llamado de alerta que acelere la

${ }^{26}$ En igual sentido: Ermida, Oscar, Sindicatos en libertad sindical, cit. (n. 16), p. 45; Palomeque, Manuel - Álvarez de la Rosa, Manuel, Derecho del Trabajo, cit. (n. 18), p. 247.

${ }^{27}$ Ver: OIT, La libertad sindical. Recopilación de decisiones y principios del Comité de Libertad Sindical del Consejo de Administración de la OIT (5a Edición revisada, Ginebra, Suiza, 2006). Así, por ejemplo, el Comité de Libertad Sindical ha resuelto que: "El derecho de negociar libremente con los empleadores las condiciones de trabajo constituye un elemento esencial de la libertad sindical, y los sindicatos deberían tener el derecho, mediante negociaciones colectivas o por otros medios lícitos, de tratar de mejorar las condiciones de vida y de trabajo de aquellos a quienes representan, mientras que las autoridades públicas deben abstenerse de intervenir de forma que este derecho sea coartado o su legítimo ejercicio impedido." En este sentido: Recopilación de 1996, párrafo 782; $310^{\circ}$ informe, caso $\mathrm{N}^{\circ} 1928$, párrafo $175 ; 311^{\circ}$; informe, caso $\mathrm{N}^{\circ} 1951$, párrafo 220; caso $\mathrm{N}^{\circ} 1942$, párrafo 269; 321; informe, caso $\mathrm{N}^{\circ} 2019$, párrafo $412 ; 327^{\circ}$ informe, caso $\mathrm{N}^{\circ} 2119$, párrafo 253 y 338 , informe, caso $\mathrm{N}^{\circ} 2326$, párrafo 459.

${ }^{28}$ Véase: Ugarte Cataldo, José Luis, Libertad sindical y Constitución, cit. (n. 13). 
adopción de medidas tendientes mejorar la precaria situación en que se encuentra la dimensión colectiva de la libertad sindical.

\section{EL RECONOCIMIENTO DE LA LIBERTAD SINDICAL EN LOS CONVENIOS DE LA OIT Y SU INCIDENCIA EN EL DERECHO CHILENO}

La OIT se ha preocupado prácticamente desde sus comienzos de la necesidad de asegurar normas y principios básicos sobre la libertad sindical que tengan vigencia y validez para todos los países que la integran, lo que se ha materializado en la aprobación de distintos Convenios, siendo los más relevantes el $\mathrm{N}^{\circ} 87$ de 1948, sobre libertad sindical y protección del derecho de sindicación y el Convenio $\mathrm{N}^{\circ} 98$ de 1949, sobre el derecho de sindicación y de negociación colectiva ${ }^{29}$.

Los Convenios referidos se complementan directamente con otros instrumentos internacionales aprobados en el seno de la OIT, entre los que cabe destacar: el Convenio $\mathrm{N}^{\circ} 135$ de 1971, sobre la protección y facilidades que deben otorgarse en la empresa a los representantes de los trabajadores $^{30}$; el Convenio $\mathrm{N}^{\circ} 141$ de 1975, sobre organizaciones rurales ${ }^{31}$; el Convenio $\mathrm{N}^{\circ} 151$ de 1978, sobre protección del derecho de sindicación y los procedimientos para determinar las condiciones de empleo en la administración pública ${ }^{32}$; y el Convenio $\mathrm{N}^{\circ} 154$ de 1981, sobre promoción de la negociación colectiva ${ }^{33}$.

Asimismo, en la constante búsqueda de la OIT por reforzar el valor de libertad sindical como un derecho fundamental debe tenerse en especial consideración la Declaración relativa a los Principios y Derechos Fundamentales en el Trabajo, de 1998, la que en sus considerandos destaca que: "[...] el crecimiento económico es esencial, pero no suficiente, para asegurar la equidad, el progreso social y la erradicación de la pobreza, lo que confirma la necesidad de que la OIT promueva politicas sociales sólidas, la justicia e instituciones democráticas". Por lo anterior, se sostiene por este organismo que: "[...] con el objeto de mantener el vinculo entre progreso social y crecimiento económico, la garantía de los principios y derechos fundamentales en el trabajo reviste una importancia y un significado especiales al asegurar a los propios interesados la posibilidad de reivindicar libremente y en igualdad de

\footnotetext{
${ }^{29}$ Ambos Convenios fueron ratificados por Chile después de haber transcurrido 50 años desde su emisión; Diario Oficial de fecha 12 de mayo de 1999.

${ }^{30}$ Ratificado por Chile, Diario Oficial de fecha 29 de julio de 2000.

${ }^{31}$ Este Convenio aún no ha sido ratificado por Chile.

${ }^{32}$ Ratificado por Chile, Diario Oficial de fecha 26 de diciembre de 2000.

${ }^{33}$ Este Convenio aún no ha sido ratificado por Chile.
} 
oportunidades una participación justa en las riquezas a cuya creación han contribuido, así como la de desarrollar plenamente su potencial humano".

A continuación, en el punto 2 de la Declaración se contiene lo que constituye sin lugar a dudas el núcleo central y programático de este instrumento internacional, en el que se señala que: "todos los Miembros, aun cuando no hayan ratificado los Convenios, tienen un compromiso que se deriva de su mera pertenencia a la Organización de respetar, promover y hacer realidad, de buena fe y de conformidad con la Constitución, los principios relativos a los derechos fundamentales que son objeto de esos Convenios, es decir: i) la libertad de asociación y la libertad sindical y el reconocimiento efectivo del derecho de negociación colectiva; ii) la eliminación de todas las formas de trabajo forzoso u obligatorio; iii) la abolición efectiva del trabajo infantil; y iv) la eliminación de la discriminación en materia de empleo y ocupación".

Así, entonces, queda claro el lugar central que ocupa para la OIT el reconocimiento de la libertad sindical como derecho fundamental de validez universal y el deber ineludible de todos los Estados miembros de ese organismo por materializar su vigencia efectiva, dado su rol primordial como presupuesto del "trabajo decente" 34 .

A la luz de lo que constituye el contenido central de los Convenios $\mathrm{N}^{\circ} 87$ y 98 de la OIT, cabe destacar como aspectos más relevantes del reconocimiento a la libertad sindical que:

i) Los trabajadores y los empleadores deben tener absoluta libertad para constituir las organizaciones sindicales que estimen convenientes ${ }^{35}$, como para afiliarse a éstas, sin otra condición que la de respetar sus estatutos (artículo 2 del Convenio $\mathrm{N}^{\circ} 87$ );

ii) Las organizaciones de trabajadores deben tener el derecho a redactar sus estatutos y reglamentos, el de elegir libremente a sus representantes, el de organizar su administración y sus actividades, y el derecho de formular su programa de acción. Lo anterior debe poder efectuarse sin intervención de las autoridades públicas que puedan limitar o entorpecer el ejercicio de este derecho (artículo 3 del Convenio $\mathrm{N}^{\circ} 87$ ).

iii) Las organizaciones de trabajadores deben tener el derecho a constituir federaciones o confederaciones, así como a afiliarse a las mismas, sean éstas nacionales o internacionales (artículo 5 del Convenio $\mathrm{N}^{\circ} 87$ ).

iv) La adquisición de la personalidad jurídica de las asociaciones de trabajadores no debe estar sujeta a condiciones cuya naturaleza limite la

${ }^{34}$ Véase: Espinoza, Malva, Trabajo decente y protección social (Santiago, Oficina Internacional del Trabajo, Chile, 2003).

${ }^{35}$ El artículo 10 del Convenio $N^{\circ} 87$ dispone que: "En el presente Convenio, el término organización significa toda organización de trabajadores o de empleadores que tenga por objeto fomentar y defender los intereses de los trabajadores o de los empleadores". 
aplicación de las disposiciones del Convenio (artículo 7 del Convenio $\mathrm{N}^{\circ} 87$ )

v) La OIT reconoce en sus Convenios que el reconocimiento de la libertad sindical no es absoluta y debe ejercerse de acuerdo a las condiciones específicas de cada país (artículo 8 del Convenio $\mathrm{N}^{\circ} 87$ ).

vi) La huelga no es tratada explícitamente en el Convenio No 87, pero el Comité de Libertad Sindical del Consejo de Administración de la OIT y la Comisión de Expertos en la aplicación de Convenios y Recomendaciones, órganos establecidos para el control de la aplicación de las normas de la OIT, han señalado que está implicada en el contenido de los artículos 3 y 10 del citado Convenio y desde ahí han reconocido el derecho de huelga como un derecho fundamental de los trabajadores y de sus organizaciones y delimitado su ejercicio. Asimismo, el Comité de Libertad Sindical ha sostenido que el derecho a huelga es un corolario indisociable del derecho de asociación reconocido por el Convenio $\mathrm{N}^{\circ} 87$, constituyendo uno de los derechos fundamentales de los trabajadores y de sus organizaciones en la medida que sea un medio de defensa de sus intereses colectivos ${ }^{36}$.

vii) Se establece una tutela amplia de la libertad sindical. Es así como los trabajadores deberán gozar de adecuada protección contra todo acto de discriminación tendiente a menoscabar la libertad sindical en relación con su empleo (artículo 1 del Convenio $\mathrm{N}^{\circ}$ 98). De igual manera, las organizaciones de trabajadores y de empleadores deberán gozar de adecuada protección contra todo acto de injerencia ${ }^{37}$ de unas respecto de las otras, ya se realice directamente o por medio de sus agentes o miembros, en su constitución, funcionamiento o administración (artículo 2 del Convenio $\mathrm{N}^{\circ}$ 98).

viii) Deberán adoptarse medidas adecuadas a las condiciones nacionales, cuando ello sea necesario, para estimular y fomentar entre los empleadores y las organizaciones de empleadores, por una parte, y las organizaciones de trabajadores, por otra, el pleno desarrollo y uso de procedimientos de negociación voluntaria, con objeto de reglamentar, por medio de contratos colectivos, las condiciones de empleo (artículo 4 del Convenio $\mathrm{N}^{\circ}$ 98).

${ }^{36}$ OIT, La libertad sindical. Recopilación de decisiones y principios del Comité de Libertad Sindical del Consejo de Administración de la OIT, cit. (n. 27), párrafo 523 y 520 .

${ }^{37} \mathrm{El}$ artículo 2 apartado 2 del Convenio No 98 dispone que: "Se consideran actos de injerencia, en el sentido del presente articulo, principalmente, las medidas que tiendan a fomentar la constitución de organizaciones de trabajadores dominadas por un empleador o una organización de empleadores, o a sostener económicamente, o en otra forma, organizaciones de trabajadores, con objeto de colocar estas organizaciones bajo el control de un empleador o de una organización de empleadores". 
En relación con esta disposición, resulta interesante señalar que es la única que se refiere a la negociación colectiva, lo que encuentra una explicación en la visión de la OIT en aquel entonces y en el contexto histórico en el que el Convenio fue dictado, sin embargo, como el mismo organismo internacional lo ha recalcado en otros instrumentos posteriores, particularmente en el Convenio $\mathrm{N}^{\circ} 154$ de 1981, la negociación colectiva forma parte indiscutida de la libertad sindical y existe un deber de los Estados miembros de la OIT de fomentarla y de hacer realidad su ejercicio. ${ }^{38}$ Ello es así, porque en el momento actual la sociedad democrática instaura a la libre sindicación y al derecho a la negociación colectiva como principios básicos del estado social, reflejando de esa forma su papel central y emplazándolos como fundamentos de la democracia. De esta manera, se reconoce el papel equilibrador de las asociaciones ligadas al ámbito laboral y la importancia de sus medios de acción, a la vez que sitúa lo social como clave de la existencia del propio Estado ${ }^{39}$.

Sin desconocer lo anterior, se debe hacer presente que en materia de negociación colectiva el principal Convenio de la OIT es el $\mathrm{N}^{\circ} 154$, en el que se precisa y desarrollan las normas generales contenidas en el Convenio $\mathrm{N}^{\circ}$ 98, tal como lo señala su propio preámbulo. En el Convenio $\mathrm{N}^{\circ} 154$ se contiene una definición de negociación colectiva, señalando que esta comprende: "[...] todas las negociaciones que tienen lugar entre un empleador, un grupo de empleadores o una organización o varias organizaciones de empleadores, por una parte, y una organización o varias organizaciones de trabajadores, por otra, con el fin de: a) fijar las condiciones de trabajo y empleo, o b) regular las relaciones entre empleadores y trabajadores, o c) regular las relaciones entre empleadores o sus organizaciones y una organización o varias organizaciones de trabajadores, o lograr todos estos fines a la vez". A continuación, la otra norma central de este Convenio, el artículo 5, precisa de qué manera deben llevarse a cabo las actividades de fomento de la negociación colectiva y dispone: "Se deberán adoptar medidas adecuadas a las condiciones nacionales para fomentar la negociación colectiva. [...]/ 2. Las medidas a que se refiere el párrafo 1 de este articulo deberán tener por objeto que:/ a) la negociación colectiva sea posibilitada a todos los empleadores y a todas las categorias de trabajadores de las ramas de actividad a que se aplique el presente Convenio;/ b) la negociación colectiva sea progresivamente extendida a todas

${ }^{38}$ En igual sentido: ERmida, Oscar, Sindicatos en libertad sindical, cit. (n. 16), pp. $45 \mathrm{~s}$.

${ }^{39}$ Vega-Ruiz, María, Libertad de asociación, libertad sindical y el reconocimiento efectivo del derecho de negociación colectiva en América Latina. El desarrollo práctico de un principio fundamental (Programa Infocus para la promoción de la Declaración relativa a los Principios y Derechos Fundamentales en el Trabajo, OIT, 2003), p. 9. 
Las materias a que se refieren los apartados a), b) yc) del articulo 2 del presente Convenio;/ c) sea fomentado el establecimiento de reglas de procedimiento convenidas entre las organizaciones de los empleadores y las organizaciones de los trabajadores;/ d) la negociación colectiva no resulte obstaculizada por la inexistencia de reglas que rijan su desarrollo o la insuficiencia o el carácter impropio de tales reglas;/ e) los órganos y procedimientos de solución de los conflictos laborales estén concebidos de tal manera que contribuyan a fomentar la negociación colectiva".

En lo que respecta a la incidencia de esta normativa internacional respecto de nuestro Derecho Interno, cabe señalar que al ser Chile miembro de la OIT se encuentra en la necesidad, tal como lo plantea categóricamente el apartado 2 de la Declaración relativa los Principios y Derechos Fundamentales en el Trabajo de 1998, de hacer realidad, de buena fe, el reconocimiento efectivo del derecho a la negociación colectiva, lo que supone una serie de deberes tendientes a promover este derecho y a ampliar el número de trabajadores cubiertos por los beneficios de los instrumentos colectivos. Además, dentro de estos deberes se encuentra naturalmente el de propiciar reformas al ordenamiento jurídico laboral, cuando ello sea necesario para poder materializar el pleno ejercicio de este derecho fundamental. En efecto, este último deber de adecuar la normativa interna, resulta claro e indiscutido, de acuerdo con las disposiciones de la Constitución de la OIT, debido a que el país ha ratificado los Convenios $\mathrm{N}^{\circ} 87$ y 98 . De allí entonces, que parte fundamental de la reforma laboral introducida por la Ley $\mathrm{N}^{\circ} 19.759$ de 2001 al CdT apuntó, precisamente, a concordar nuestra legislación interna con las normas y principios de dichos instrumentos internacionales ${ }^{40}$ lo que implicó una reforma sustantiva al Derecho Sindical, caracterizado hasta antes de dicha reforma por su excesiva reglamentación y por limitaciones directas e indirectas que se imponían al libre ejercicio de la autonomía colectiva ${ }^{41}$.

${ }^{40}$ Véase el Punto I.1. del Mensaje con el cual el Presidente Ricardo Lagos envió el proyecto de ley de reforma laboral al Congreso Nacional, "Mensaje" No 136-343, de fecha 16 de noviembre de 2000.

${ }^{41}$ Según lo manifiesta Tapia Guerrero, Francisco, Sindicatos en el Derecho Chileno del Trabajo (Editorial LexisNexis, Santiago, Chile, 2005), pp. 187-188, este ajuste de nuestra normativa interna con los Convenios internacionales se efectuó mediante: a) el reconocimiento efectivo del derecho de sindicalización, en términos de que los trabajadores pueden constituir las organizaciones sindicales que estimen convenientes, ampliándose la tipología sindical y disminuyéndose los quórum de constitución de sindicatos, así como favoreciendo la constitución de un primer sindicato al nivel de empresa a través de un quórum promocional. b) La consagración de la más amplia autonomía sindical con el retiro de la intervención fiscalizadora del Estado y la remisión de su funcionamiento al estatuto sindical; eliminando requisitos 
Con todo, aun cuando Chile no haya ratificado todavía el Convenio $N^{\circ} 154$, que es explícito en el deber de promover la negociación colectiva, ello no impide que se propicie una mayor cobertura y efectividad de la negociación colectiva, por aplicación de lo dispuesto en el artículo 4 del Convenio No 98. Refuerza esta necesidad la circunstancia de que los Convenios de la OIT reconocen derechos fundamentales, los que por aplicación del artículo 5 inciso 2 de la Constitución Política de la República deben ser respetados y promovidos, representando ello un claro deber para el Estado de Chile. Hasta la fecha, con ocasión de la reforma laboral del año 2001 se hicieron muy pocas modificaciones, todas ellas no sustanciales al CdT en materia de negociación colectiva y de huelga, por lo que la doctrina iuslaboralista nacional ${ }^{42}$ está de acuerdo en afirmar que en dos de los pilares básicos de la libertad sindical - la negociación colectiva y la huelga - Chile mantiene aún prácticamente incólume la visión restrictiva del ejercicio de estos derechos heredada del Plan Laboral.

Por tanto, atendido lo precedentemente expuesto, se puede sostener que una postura pasiva y acrítica frente a la problemática que origina la actual normativa sobre negociación colectiva no es posible, en base al claro mandato de la Declaración relativa a los Principios y Derechos Fundamentales del Trabajo, así como por el deber en que se encuentra Chile de adecuar la legislación laboral al contenido esencial de los Convenios No 87 y No 98 de la OIT, los que obligan a los Estados ratificantes a promover de la negociación colectiva ${ }^{43}$. Asimismo, creemos que resulta imperioso perfeccionar la actual institucionalidad laboral sobre la negociación colectiva, porque existe una realidad indesmentible en nuestro mercado de trabajo que plantea como un desafío social ineludible la necesidad de intervenir para poner fin a la baja incidencia que hoy tiene el ejercicio de los derechos colectivos, lo que repercute en una creciente inequidad salarial, agravada por la falta de otros mecanismos adecuados de redistribución de ingresos.

de elegibilidad de sus representantes y estableciendo un régimen electoral autónomo. c) El reforzamiento de la libertad sindical a través de normas represivas de las conductas antisindicales, sea que se trate o no de trabajadores amparados por el fuero sindical. Véase asimismo: Tapia Guerrero, Francisco, Modificaciones al Derecho Sindical en la Ley No 19.759, en Revista Laboral Chilena (enero 2002), pp. 84 s.

${ }^{42}$ Entre otros, Gamonal Contreras, Sergio, Derecho Colectivo del Trabajo, cit. (n. 13), pp. 237 s.; Rojas Miño, Irene, Las reformas laborales, cit. (n. 5), pp. 217218.

${ }^{43}$ Así lo dispone expresamente el artículo 4 del Convenio No 98 de la OIT. 


\section{SUJETOS ACTIVOS EN LA NEGOCIACIÓN COLECTIVA: EL DILEMA ENTRE LOS SINDICATOS Y LOS GRUPOS DE TRABAJADORES}

Una de las normas más controvertidas y, a la vez, emblemáticas del modelo de relaciones colectivas impuesto por el Plan Laboral es aquella que equipara a sindicatos y a grupos de trabajadores reunidos para el sólo efecto de negociar colectivamente como sujetos intervinientes de la negociación colectiva. Así lo señala expresamente el artículo 303 del CdT que define a la negociación colectiva señalando que es un procedimiento en el que uno o más empleadores se relacionan con una o más organizaciones sindicales o con trabajadores que se unan para tal efecto, o con unos y otros, con el objeto de establecer condiciones comunes de trabajo y de remuneraciones por un tiempo determinado. Este criterio es confirmado por el artículo 315 del CdT al establecer que: "La negociación colectiva se iniciará con la presentación de un proyecto de contrato colectivo por parte del o los sindicatos o grupos negociadores de la respectiva empresa".

Con la equiparación de los sindicatos y los grupos negociadores el Régimen Militar buscó debilitar el poder de los sindicatos, como una clara reacción al rol político que estos tuvieron en el período anterior a 1973. A su vez, desde una perspectiva económica, la reforma pretendió derechamente poner fin al rol protagónico exclusivo o monopólico en la negociación colectiva, desarticulando su poder negociador, colocando en una posición de preeminencia a los intereses del empleador y de la empresa. Como lo sostiene Irene Rojas, ${ }^{44}$ el Plan Laboral definió la titularidad en la negociación colectiva. Por la parte empresarial, es el respectivo empleador de la empresa de que se trate, mientras que por la parte laboral el modelo normativo estableció una doble titularidad: la del sindicato de empresa y la del grupo de trabajadores que se organizare para tal fin; pudiendo existir al interior de cada empresa una multiplicidad de titulares de los trabajadores, pero que sólo representan los intereses de los trabajadores afiliados o adheridos a cada sindicato o grupo negociador. En lo que respecta al objetivo de admitir la titularidad a una coalición de trabajadores, la autora citada manifiesta que el sólo hecho de que se reconozca como acuerdo colectivo al suscrito por una coalición transitoria de trabajadores plantea objeciones de política legislativa, por los peligros que encierra una estructura de negociación colectiva sin administradores de los instrumentos colectivos por la parte laboral, peligro que se suma al escaso margen que este modelo normativo reconoce a las partes sociales para el ejercicio de la autonomía colectiva. Una consecuencia natural de lo anterior es

\footnotetext{
${ }^{44}$ Rojas Miño, Irene, Las reformas laborales, cit. (n. 5), pp. 204-205.
} 
el paralelismo organizacional al interior de una misma empresa, pues el mismo modelo normativo permite el paralelismo sindical al interior de la entidad que sirve de base a la constitución de sindicatos, es decir, la empresa. Por un lado, se pueden constituir tantas organizaciones sindicales reúnan los quórum mínimos y, por otro, no se reconoce derecho alguno al sindicato más representativo. A la vez, se le reconoce espacio a los grupos de trabajadores representantes de fraccionados intereses laborales, lo que ha generado un espacio eficaz para las presiones empresariales tendientes a eliminar la organización sindical, asimismo para quitar eficiencia a la negociación colectiva o generar seudos acuerdos colectivos, como han sido los convenios colectivos suscritos por coaliciones de trabajadores. Si bien las bases del Plan Laboral no señalan los fundamentos de esta medida, el conjunto de ellas permite suponer la atomización de la parte laboral y, consecuencialmente, la pérdida de su poder negociador.

Por otra parte, cabe agregar que según Sergio Gamonal ${ }^{45}$, la igualdad con que la legislación contempla a las coaliciones transitorias de trabajadores en relación con los sindicatos atenta contra el principio de libertad sindical, pues posibilita que existiendo sindicatos en una empresa, una coalición transitoria de trabajadores pudiera negociar colectivamente, lo que favorece la influencia del empleador sobre la misma y la posibilidad de divisiones u otras prácticas desleales inducidas por el empleador. Además, el legislador promueve indirectamente a las coaliciones transitorias de trabajadores al establecer condiciones de menor exigencia para que puedan negociar colectivamente. Es así, como el artículo 315 inciso 3 del CdT señala que para poder negociar colectivamente los grupos de trabajadores deben reunir, a lo menos, los mismos quórum y porcentajes requeridos para la constitución de un sindicato de empresa o el de un establecimiento de ella, lo que a primera vista podría llevar a pensar que sería más conveniente constituir un sindicato, dado el carácter permanente de esta organización. Sin embargo, ello no es así, pues el aludido inciso 3 prescribe que estos quórum y porcentajes se entenderán referidos al total de los trabajadores facultados para negociar colectivamente que laboren en la empresa, en el predio o en el establecimiento según el caso. Por tal motivo, si se pondera la norma en detalle se llega a la conclusión de que las exigencias legales para los grupos son inferiores que las requeridas para la constitución de un sindicato, ya que respecto de estos se determinan en base a todos los trabajadores de la empresa, predio o establecimiento, mientras que si se trata de un grupo de trabajadores que se forma para el sólo fin de negociar

${ }^{45}$ Gamonal Contreras, Sergio, Derecho colectivo del trabajo, cit. (n. 13), pp. 260-261. 
colectivamente, estas exigencias se determinan sólo en base al total de los trabajadores facultados para negociar colectivamente.

Sin perjuicio de lo anterior, se debe recalcar que la OIT, particularmente el Comité de Libertad Sindical, ha denunciado reiteradas veces la vulneración a la libertad sindical que supone la equiparación de los grupos de trabajadores con los sindicatos; debido a ello, su reconocimiento, aceptación y promoción indirecta por parte del actual ordenamiento jurídico laboral chileno atenta contra esta garantía fundamental e implica una clara vulneración de los acuerdos internacionales ratificados por el país, particularmente los Convenios $N^{\circ} 87$ y 98 de la OIT, así como un desconocimiento de los postulados esenciales de la Declaración relativa a los Principios y Derechos Fundamentales en el Trabajo de 1998. A mayor abundamiento, el Comité de Libertad Sindical ha resuelto que: "La recomendación sobre los contratos colectivos ( $N^{\circ} 91$ de 1951) da preeminencia, en cuanto a una de las partes de la negociación colectiva, a las organizaciones de trabajadores, refiriéndose a los representantes de los trabajadores no organizados solamente en el caso de ausencia de tales organizaciones. En estas circunstancias, la negociación directa entre la empresa y sus trabajadores, por encima de las organizaciones representativas cuando las mismas existen, puede en ciertos casos ir en detrimento del principio por el cual se debe estimular y fomentar la negociación colectiva entre empleadores y organizaciones de trabajadores"46.

Por estas razones, no compartimos la opinión de Celhay y Gil ${ }^{47}$, quienes con una visión más bien cuantitativa, vinculada a la baja incidencia de la existencia de los grupos de empresa en las tasas de sindicalización, no ven mayores obstáculos en mantener el reconocimiento de los grupos si es que "razones culturales" permiten establecer que su eliminación no implicaría un aumento del número de trabajadores afiliados a un sindicato. Un argumento de esta naturaleza, desconoce el sentido claro de la libertad sindical y condiciona su pleno ejercicio a variables cuantitativas que no son admisibles cuando se trata de articular un modelo normativo que respete los derechos fundamentales de los trabajadores y que no desconozca garantías que son imprescindibles para que los actores puedan interrelacionarse en plano de igualdad, no sólo al momento de la negociación, sino que durante toda la vigencia de los respectivos instrumentos colectivos. Por el contrario, como lo manifiesta el profesor Walker ${ }^{48}$, la tendencia moderna

${ }^{46}$ OIT, La libertad sindical. Recopilación de decisiones y principios del Comité de Libertad Sindical del Consejo de Administración de la OIT, cit. (n. 27), párrafo 944.

${ }^{47}$ Celhay, Pablo; Gil, Diego, Sindicalización y negociación colectiva, cit. (n. 1), p. 17.

${ }^{48}$ Walker Errázuriz, Francisco, Derecho de las relaciones laborales (Santiago, Editorial Universitaria, 2003), p. 561-562. 
es que la organización sindical existente o las organizaciones más representativas, en caso de pluralidad sindical en el nivel que corresponda, sea quien represente a los trabajadores en la negociación colectiva. Este criterio corresponde a lo sustentado por la OIT a través del Convenio No 98 y los demás instrumentos que se refieren a la negociación colectiva, particularmente la Recomendación No 91 de 1951 sobre los contratos colectivos y el Convenio No 135 de 1971 relativo a la protección y facilidades que deben otorgarse a los representantes de los trabajadores en la empresa. Lo anterior significa que poseen la titularidad del derecho a negociación colectiva las organizaciones sindicales y, en ausencia de tales organizaciones, los representantes de los trabajadores elegidos directamente.

Para reafirmar lo precedentemente expuesto, cabe destacar que el Comité de Libertad Sindical de la OIT ha señalado también que: "En el Convenio sobre los representantes de los trabajadores ( $N^{\circ} 135$ de 1971) y en el Convenio sobre la negociación colectiva ( $N^{\circ} 154$ de 1981) figuran disposiciones expresas para garantizar que cuando en una misma empresa existan sindicatos y representantes elegidos por los trabajadores, se adopten medidas apropiadas para garantizar que la existencia de representantes electos no se utilice en menoscabo de la posición de los sindicatos interesados ${ }^{\prime 49}$. A su vez, se ha entendido que: "[...] la negociación colectiva, a través de arreglos directos concluidos entre un empleador y un grupo no sindicalizado de trabajadores, aun habiendo sindicato en la empresa, no promueve la negociación colectiva en el sentido del artículo 4 del Convenio $N^{\circ} 98$, que se refiere al fomento de la negociación entre los empleadores y sus organizaciones y las organizaciones de trabajadores" ${ }^{\text {. }}$.

Sin perjuicio de lo anterior y, recogiendo los planteamientos del mismo Comité de Libertad Sindical de la OIT, nada obsta a que de manera excepcional se permita la existencia de grupos de trabajadores que se reúnan para negociar colectivamente en aquellas situaciones en que no exista (o no se pueda constituir) una organización sindical que pueda asumir la defensa de los intereses colectivos de los trabajadores, pues de esta manera se posibilita y no se entraba, el ejercicio de este derecho fundamental. Esto último podría ser especialmente provechoso en las PYME, sobre todos en las pequeñas y microempresas, ya que por regla general no existe en ellas el quórum mínimo de trabajadores para constituir un sindicato, por lo que la posibilidad de negociar colectivamente, al menos como grupo, le permitiría a estos trabajadores ejercer un derecho fundamental que hoy

${ }^{49}$ OIT, La libertad sindical. Recopilación de decisiones y principios del Comité de Libertad Sindical del Consejo de Administración de la OIT, cit. (n. 27), párrafo 946.

${ }^{50} \mathrm{OIT}$, La libertad sindical. Recopilación de decisiones y principios del Comité de Libertad Sindical del Consejo de Administración de la OIT, cit. (n. 27), párrafo 876. 
se encuentran absolutamente imposibilitados de ejercer, configurándose por tal motivo otra vulneración a la libertad sindical. Además, el reconocimiento excepcional a los grupos de trabajadores puede ser una medida que se complemente con la posibilidad de reconocer también en Chile una participación activa en la negociación colectiva a otros tipos de organizaciones sindicales distintas de los sindicatos de empresa o de establecimiento, como podría ser el caso por ejemplo, de los sindicatos interempresa.

Finalmente, en relación con esta materia cabe formular otra crítica de relevancia al actual ordenamiento jurídico laboral. La estructura de nuestro modelo de negociación colectiva impone que el tipo de sindicato que represente a los trabajadores en la empresa sea un sindicato de base, específicamente un sindicato de empresa (o de establecimiento de empresa), en virtud de lo dispuesto por el artículo 315 del CdT, a diferencia de lo que ocurre en la mayoría de las legislaciones comparadas en las cuales el sindicato se organiza más bien por rama, sin perjuicio de que pueda representar a los trabajadores de una determinada empresa frente a sus empleadores $^{51}$. De esta manera, nuestra legislación al determinar imperativamente el tipo de sindicato que represente a los trabajadores en la negociación colectiva está transgrediendo la libertad sindical, al impedir que sean los propios trabajadores organizados colectivamente, en base a la forma o tipo de organización sindical que mejor se ajuste a sus intereses, quienes decidan cómo llevar adelante la negociación ${ }^{52}$. A su vez, con esta imposición normativa nuestro $\mathrm{CdT}$ es inconsecuente con el debido respeto al principio de la libertad sindical, ya que si bien la reforma laboral introducida por la Ley $\mathrm{N}^{\circ} 19.759$ hizo posible modificar el artículo 216 de este cuerpo legal, poniendo fin a la taxatividad con la que se establecían los tipos de sindicatos base ${ }^{53}$, la modificación terminó siendo puramente simbólica, toda vez que no estableció reglas concretas que sirvieran de base

${ }^{51}$ Este es el caso, por ejemplo, del Derecho español. Sobre la materia: Albiol Montesinos, Ignacio - Camps Ruiz, Luis - López Gandía, Juan - Sala Franco, Tomás, Derecho del Trabajo, I: Fuentes y Relaciones Colectivas (5a edición, Valencia, Editorial Tirant Lo Blanch, 2003), pp. 421 s. Esta misma situación es también posible en el Derecho del Trabajo alemán, de acuerdo a lo dispuesto por el $₫ 2$ inciso $1^{\circ}$ de la Tarifvertragsgesetz, si bien constituye una excepción a la regla general conformada por la negociación colectiva a nivel de sector o rama de actividad. En detalle: Preis, Ulrich, Arbeitsrecht, cit. (n. 20), pp. 94 s.

${ }^{52}$ En este sentido: Gamonal Contreras, Sergio, Derecho Colectivo del Trabajo, cit. (n. 13), p. 262.

${ }^{53}$ Cabe recordar que la Ley $\mathrm{N}^{\circ} 19.759$ incorporó las palabras "entre otras" al enunciado del artículo 216 del CdT, por lo que en teoría es posible constituir cualquier forma de organización sindical de base, distintas a la que esta disposición legal determina y define. 
a su constitución y, en concreto, nada señaló acerca de su derecho de negociar colectivamente. No obstante, por aplicación de las reglas generales, artículo $220 \mathrm{~N}^{\circ} 1$ y 314 del CdT se podría llegar a concluir que podrían negociar de manera no reglada, pero ello no permite sostener que se esté respetando la libertad sindical, ya que esa clase de negociación no obliga al empleador a negociar, como a su vez, no le reconoce a las organizaciones sindicales el derecho a huelga ni protege a los trabajadores involucrados en la negociación con el fuero ${ }^{54}$.

En definitiva, se puede sostener que, en la materia analizada en este acápite, a pesar de las reformas legales del año 1990 y 2001, aún no es posible verificar un adecuado respeto de la libertad sindical ni una promoción efectiva del derecho fundamental a la negociación colectiva en Chile; ello, porque se mantienen inalterados hasta la fecha los principios restrictivos del Plan Laboral que buscaron desarticular el movimiento sindical y restarle poder negociador a las organizaciones sindicales, con lo cual un número creciente de trabajadores se ha visto imposibilitado hasta la fecha para optar a un mejoramiento de sus condiciones generales de trabajo por la vía del ejercicio de los derechos colectivos.

\section{CONCLUSIÓN}

Según se ha podido establecer en el desarrollo de este estudio, la legislación laboral vigente contenida en el CdT no está en concordancia con el debido respeto de la libertad sindical, a pesar de las últimas reformas implementadas en el país, particularmente, luego de la ratificación de los Convenios No 87 y 98 de la OIT. Esta deficiencia normativa tiene enormes implicancias jurídicas para Chile frente a la OIT y ante la comunidad internacional, por cuanto conlleva una subvaloración de una garantía que es esencial para que el aseguramiento de lo que la OIT denomina una "globalización justa que genere oportunidades de trabajo decente para hombres y mujeres, en condiciones de libertad, seguridad y dignidad humana" 55 , como a su vez, implica un claro incumplimiento de las obligaciones asumidas al ratificar los tratados que reconocen a la libertad sindical como un derecho fundamental. Por lo tanto, como lo sostiene con acierto Irene Rojas, ${ }^{56}$ es indudable que en Chile está pendiente la tarea de definir un modelo normativo de negociación colectiva que esté en concordancia con el claro mandato de los convenios de la OIT sobre la libertad sindical.

\footnotetext{
${ }^{54}$ Con la misma opinión: Gamonal Contreras, Sergio, Derecho Colectivo del Trabajo, cit. (n. 13), p. 123.

${ }^{55}$ Sobre el particular véase el sitio web de la OIT en www.ilo.org.

${ }^{56}$ Rojas Miño, Irene, Las reformas laborales, cit. (n. 5), p. 220.
} 
Creemos, por tanto, que desde la perspectiva iuslaboralista no se puede permanecer indiferente ante el impacto económico que supone un limitado y restrictivo ejercicio de los derechos de sindicación y de negociación colectiva, cuyo reflejo aparece de manifiesto en encuestas como la ENCLA 2006 ya citadas. En los últimos años, la legislación laboral influenciada por una visión económica y política heredera del Plan Laboral, ha dificultado los avances en el respeto y promoción de la libertad sindical, sin perjuicio de contribuir a la generación de bases falsas a partir de las cuales se sustenta la competitividad del país en el ámbito del comercio internacional, en razón de los bajos costos laborales que se derivan de un sistema normativo que dificulta la actividad sindical, la negociación colectiva y el diálogo social, todo lo cual obra en desmedro de una competitividad fundada en la eficiencia de los procesos productivos y en la calidad de los productos o servicios que son objeto de exportación.

Por último, desde esta perspectiva crítica de la legislación laboral a la luz de la libertad sindical no es posible obviar que el CdT contiene normas que desincentivan la actuación en la negociación colectiva de organizaciones permanentes de trabajadores que puedan hacer valer íntegramente los intereses colectivos de sus asociados, como asimismo, contribuye a la división y atomización del poder negociador de los sindicatos, en provecho de los intereses empresariales. Urge, por tanto, una reforma legal que suprima a las coaliciones transitorias de los trabajadores como sujetos de la negociación colectiva. Con todo, no deja de ser preocupante que, luego de transcurridos casi 20 años desde la implementación del Plan Laboral a través de la dictación del $\mathrm{DL} \mathrm{N}^{\circ} 2.758$, no se hayan podido aprobar modificaciones a esta norma que atenta contra la libertad sindical y que se opone tan directamente a las normas y principios de la OIT sobre la materia. Mientras esto no ocurra, es indudable que el Estado chileno no estará en condiciones de cumplir cabalmente con el deber de promover el efectivo ejercicio del derecho fundamental a la negociación colectiva.

[Recibido el 9 de abril y aceptado el 5 de mayo de 2008].

\section{BIBLIOGRAFÍA}

Albiol Montesinos, Ignacio - Camps Ruiz, Luis - López Gandía, Juan; Sala Franco, Tomás; Derecho del Trabajo, Tomo I. Fuentes y Relaciones Colectivas (5a edición, Valencia, Editorial Tirant Lo Blanch, España, 2003).

CaAmaño Rojo, Eduardo, La tutela jurisdiccional de la libertad sindical, en Revista de Derecho, Universidad Austral de Chile 19 (julio 2006).

Canmaño Rojo, Eduardo, Contenido laboral del Tratado de Libre Comercio con los Estados Unidos de Norteamérica, en Revista Laboral Chilena 118 (julio 2003). 
Celhay, Pablo; Gil, Diego, Sindicalización y negociación colectiva, Estudio para el Consejo Asesor Presidencial de Trabajo y equidad, p. 5 s., disponible en: www. trabajoyequidad.cl/documentos/temp/Sindicalización.pdf.

Comisión de las Comunidades Europeas, Libro Verde. Modernizar el Derecho Laboral para afrontar los retos del siglo XXI (Bruselas, 22 de noviembre de 2006, COM (2006) 708 final).

Corvera, Diego - Gumucio, J., Las normas de los Convenios 87 y 98 de la OIT y su relación con la normativa interna chilena, en Revista Laboral Chilena (julio 2000).

Dirección del Trabajo, Encuesta Laboral, ENCLA 2006, p. 93 s. Documento disponible en: www.dt.gob.cl.

Epping, Volker, Grundrechte (2a edición, Berlín, Editorial Springer, 2005).

Ermida, Oscar, Sindicatos en libertad sindical (2a edición, Montevideo, Fundación de Cultura Universitaria, 1999).

Espinoza, Malva, Trabajo decente y protección social (Oficina Internacional del Trabajo), Santiago, Chile, 2003.

Franco, Julio; Marcos-Sánchez, José; Benoit, Christine, Negociación colectiva articulada. Una propuesta estratégica (Lima, OIT/PLADES, 2001).

Gamonal Contreras, Sergio, Derecho Colectivo del Trabajo (Santiago, Editorial LexisNexis, Chile, 2002).

Gamonal Contreras, Sergio, Daño moral en el contrato de trabajo (Santiago, Editorial LexisNexis, Chile, 2005).

Macchiavello, Guido, Derecho Colectivo del Trabajo (Santiago, Editorial Jurídica, Chile, 1989).

Mantero, Osvaldo, Derecho sindical (2a reimpresión, Montevideo, Fundación de Cultura Universitaria, 2004).

OIT, La libertad sindical. Recopilación de decisiones y principios del Comité de Libertad Sindical del Consejo de Administración de la OIT (5 Edición revisada, Ginebra, 2006).

Ortiz, Fernando, El movimiento obrero en Chile (Santiago, Lom Ediciones, Chile, 2005).

Palomeque, Manuel; Álvarez de la Rosa, Manuel, Derecho del Trabajo ( $11^{\circ}$ edición, Madrid, Editorial Centro de Estudios Ramón Areces, 2003).

PreIs, Ulrich, Arbeitsrecht. Praxis-Lehrbuch zum Kollektivarbeitsrecht (Colonia, Editorial Dr. Otto Schmidt, 2003).

Rojas Miño, Irene, Las reformas laborales al modelo normativo de negociación colectiva del Plan Laboral, en Revista Ius et Praxis 13 (2007) 2.

Sala Franco, Tomás - Albiol Montecinos, Ignacio, Derecho Sindical (9a edición, Valencia, Editorial Tirant Lo Blanch, 2003).

Salinero, Jorge - Rozas, María - TApia, Andrés, 20 años de afiliación sindical y de negociación colectiva en Chile: problemas y desafios, en Cuaderno de Investigación No 29, Departamento de Estudios de la Dirección del Trabajo (noviembre 2006), disponible en: http://www.dt.gob.cl/documentacion/1612/article-94126.html.

Tapia Guerrero, Francisco, Modificaciones al Derecho Sindical en la Ley No 19.759, en Revista Laboral Chilena (enero 2002).

Tapia Guerrero, Francisco, Sindicatos en el Derecho Chileno del Trabajo (Santiago, Editorial LexisNexis, 2005).

Thayer Arteaga, William, Hacia una nueva cultura laboral. Efectos y proyecciones de la ratificación de los Convenios 87 y 98 de la OIT (Santiago, Fundación Científica 
y Tecnológica, Asociación Chilena de Seguridad, 1999).

Toledo, César, Alcances de la negociación colectiva en Chile, Sociedad Chilena de Derecho del Trabajo (2007), documento sin editar.

Ugarte Cataldo, José Luis, Libertad sindical y Constitución: cómo superar una vieja lectura, en Revista Laboral Chilena (mayo 2000).

Varas Castillo, Mario, Libertad sindical y negociación colectiva en Chile: un diagnóstico de la Ley $N^{\circ} 19.759$, en Boletín Oficial de la Dirección del Trabajo (agosto 2003).

VegA-RuIz, María, Libertad de asociación, libertad sindical y el reconocimiento efectivo del derecho de negociación colectiva en América Latina. El desarrollo práctico de un principio fundamental (Programa Infocus para la promoción de la Declaración relativa a los Principios y Derechos Fundamentales en el Trabajo, OIT, 2003).

Walker Errázuriz, Francisco, Derecho de las relaciones laborales (Santiago, Editorial Universitaria, 2003). 
